\title{
Analysis of the Role of Autoantibodies (Anti-DNA) In Fetal Growth Restriction Syndrome in Uzbekistan
}

\author{
Mavlyanova NN* and Nadjmutdinova DK \\ Republican Specialized Scientific-Practical Medical Center of Obstetrics and Gynecology of the Ministry of Health of the Republic of \\ Uzbekistan
}

*Corresponding author: Mavlyanova NN, Republican Specialized Scientific-Practical Medical Center of Obstetrics and Gynecology of the Ministry of Health of the Republic of Uzbekistan

Keywords: Fetal growth restriction syndrome; Automine process; Autoantibodies (anti-DNA)

\section{Resume}

The article provides literature data on the significance of the study of antinuclear antibodies (anti-DNA) in systemic diseases including in obstetric pathology which are a prognostic criterion for the course of morbidity. Obstetric practice has paid particular attention to fetal growth restriction syndrome in recent years. Fetal Growth Restriction Syndrome (FGRS) is the cause of perinatal morbidity and mortality, the risk of sudden infant mortality [1]. According to WHO statistics the number of newborns with fetal growth restriction syndrome ranges from $31.1 \%$ in Central Asia to $6.5 \%$ in developed European countries. $10-15 \%$ of births have FGRS in USA, and the phenomenon of perinatal hypoxia occurs in $27-30 \%$ of children diagnosed with FGRS. The syndrome is noted with a frequency of $2.4-17 \%$ of cases according to various authors in Russia. 20\% of cases are represented by cases of FGRS, which were not diagnosed in time in the structure of perinatal mortality. In this regard, the study of etiopathogenetic reasons for the formation and peculiarities of the course of Fetal Growth Restriction Syndrome (FGRS) remains a topical problem of global health. This syndrome is based on pathological changes in fetal and/or uteroplacental complexes with a violation of compensatory mechanisms at the molecular, cellular and tissue levels. Thus transport, trophic, endocrine, metabolic, antitoxic functions of placenta, underlying the pathology of fetus and newborn are disturbed.

One of the directions of modern immunology is the doctrine about autoimmune processes caused by antigens of own tissues (autoantigens) which are accompanied by the appearance of autoreactive lymphocytes and/or autoantibodies (AAB) (Christen and von Herrath 2004). The immune system attacks the normal, healthy tissues of its own body, i.e. the body loses tolerance to its own tissue antigens. Antibodies to double-stranded DNA antibody (anti-ds DNA) belong to the group of antinuclear autoantibodies directed by the body against components of its own nuclei. It should be noted that antinuclear antibodies are typical for many diseases from the group of diffuse diseases of connective tissue, anti-dsDNA are considered specific for systemic lupus erythematosus (SLE). The detection of anti-dsDNA is one of the criteria for the diagnosis of SLE. Egner W, 2000; Fauci et al. 2008 Studies have found that a common feature of most autoimmune diseases is B-cell activation, resulting in hyperglobulinemia and excess $\mathrm{AAB}$ formation with different specificity. To date, a large number of individual autoantigens have been identified for which AAB is most commonly detected: cytoskeleton proteins and other intracellular components, DNA, RNA and nucleoproteins, phospholipids, various enzymes, hormones, receptors of various cells, etc. (Sidorik1992; Dighiero and Rose 1999). According to literature, most researchers recognize the mainly aggressive role of AAB. New function of antibodies (AB) - the ability to catalyze various biochemical reactions, i.e. to act as biological catalysts has been identified. (Tramontano et al.1986; Pollack et al. 1986; Paul et al. 1989). Similarly, to enzymes, such antibodies (AB) were called abzymes (from English word "antibody enzyme") or catalytic antibodies (CT), the presence of abzymes in the blood is a clear sign of autoimmune processes. 
Anti-dsDNA research is carried out using immunoenzyme assays. Taking into account the fact that the serum of patients with systemic diseases of connective tissue may contain several types of autoantibodies at the same time, as well as the fact that often the differential diagnosis of these diseases is based on the detection of a particular type of antibodies, when choosing a laboratory test is extremely important to consider the high specificity. The specificity of anti-dsDNA testing is $99.2 \%$ which makes this test indispensable in the differential diagnosis of systemic diseases, particularly systemic lupus erythematosus. A large number of works have been devoted to the study of both DNA-binding and DNA-hydrolysis AB especially in the field of rheumatology, endocrinology. Studies have shown that it is IgG-AB to nDNA that is responsible for the development of the disease while regarding the role of DNA-hydrolysers of $A B$ to DNA there is no unequivocal answer. Nossent HC [2], Rekvig OP [2] Among immunological aspects, an example of this autoimmune interaction is the condition in which antiphospholipid antibodies (aPL) are detected in the blood - a heterogeneous population of autoantibodies reacting with negatively charged, less often - neutral phospholipids and/or phospholipid-binding whey proteins, which is called antiphospholipid syndrome (APS). Antiphospholipid antibodies refer to immunoglobulins of $\mathrm{G}$ and $\mathrm{M}$ classes, which have negative charges. The clinical presence of antiphospholipid antibodies is characterized by thrombosis, thrombocytopenia and pregnancy termination, most often after 10 weeks Bashmakova IV [3], Alieva SA [4], Khashaeva TH [4]. Antiphospholipid antibodies bind to membrane phospholipids of thrombocytes and endothelial cells which leads to increased platelet aggregation, decrease of endogenous anticoagulant activity, appearance of thrombosis and decrease of fibrinolysis and, as a consequence, to development of thrombosis and vasoconstriction in uteroplacental complex.

According to the literature, APS occurs up to $5 \%$ of cases and the main complication of this pathology is thrombosis [5-7]. The frequency of this pathology increases to $27-42 \%$ at the primary failure to carry out pregnancy. The research of antinuclear antibodies in obstetric practice was carried out by Aleynik VA, Babich SM et al. [1]. The authors surveyed 275 women who were divided into 2 groups. The first group included 58 women who had 1 to 4 full pregnancies, the second group included 217 women who had 2 or more inevitable miscarriage in their history. The study results showed that in women of the first group antibodies to double-stranded DNA were detected in $5.7 \pm 0.7 \%$ of cases, in women of the second group these antibodies were detected in $12.5 \pm 1.1 \%$ of cases $(\mathrm{P}<0.05)$. Antibodies to single-stranded DNA in women of the first group were detected in $4.1 \pm 0.5 \%$ of cases, in women of the second group these antibodies were found in $9.3 \pm 1.2 \%(\mathrm{P}<0.001)$. Due to the fact that ss DNA is more immunogenic than ds DNA, the determination of antibodies only to ss DNA makes it possible to detect the occurrence of disease at an earlier stage [8-10]. Combined detection of DNA-ds and DNA-ss antibodies increases the diagnostic value of these antibodies. At the same time, the results of the study showed that there are changes in the rates of total immunoglobulins with a marked increase in IgG in women with habitual non carrying of pregnancy who have autoantibodies in the blood [11-15]. There is also a change in cytokine status towards a pronounced increase in pro-inflammatory interleukins and a decrease in anti-inflammatory interleukins.

Literature analysis shows that detected AABs can be an indicator of immunological reorganization and can realize their pathogenetic capabilities under certain conditions. However, finding out the problem of interconnection of catalytic activity of $A B$ to nDNA with pathogenesis and clinical manifestations of obstetric and gynecological diseases including in fetal growth restriction syndrome is the lack of a unified methodological approach to determining the significance of detectability and concentration of autoantibodies to DNA in patients' serums which will be reflected in the contradictions in the characteristic and biological role of DNA-hydrolysers and DNA-binding $\mathrm{AB}$ to nDNA in pathological processes [16,17]. Therefore, the study of the role of antinuclear antibodies to native DNA G class in serum in pregnant women with fetal growth restriction syndrome will contribute to disclosure of new pathogenetic aspects of this pathology.

\section{References}

1. Aleynik VA, Babich SM, Negmatshayeva HN, Yuldasheva OS (2017) Features of the immunological changes in women with habitual non carrying of pregnancy in the presence of autoantibodies. Young scientist 22: 411-414.

2. Nossent HC, Rekvig OP (2005) Is closer linkage between systemic lupus erythematosus and anti-double-stranded DNA antibodiesa desirable and attainable goal? Arthritis Res Ther 7(2): 85-87.

3. Bashmakova IV (2000) Problems of pregnancy. 1: 52-55.

4. Aliyeva SA, Khashaeva TH (2014) Relationship between circulation of antiphospholipid antibodies and autoimmune thyroid diseases in patients with habitual non carrying of pregnancy. Obstetrics, gynecology, and reproduction 8(4): 57.

5. Abdrakhmanova LR (2003) Determination of antinuclear antibodies in immunoincompatible pregnancy. Medical immunology 5(1): 57-66.

6. Ashurova NG (2014) Characteristics of hemocoagulation system in case of fetal intrauterine death. News of dermatovenerology and reproductive health. Tashkent 3H19014: 52-54.

7. Ayu Shcherbakov, A Ya Berdikov, V Yu (2017) Autoimmune pathology influence on the pregnancy course and delivery outcome. 13(1): 95-98.

8. Kapustina E Yu, Sandakova EA (2010) Obstetrical and perinatal aspects of the autoimmune thyroiditis. Permian medical journal 27(2): 139-143.

9. Komisszarenko YI, Bobrik MI (2016) autoimmune disorders in endocrine pathology. A new look at diagnostics and management. International Endocrinology Journal 4 (76): 41-44.

10. Mamadzhanova SO, Mirzaeva ShR, Negmatshayeva HN (2017) Peculiarities of the clinical course of pregnancy in women with antiphospholipid syndrome Medicine and Public Health: Materials of $\mathrm{V}$ International Scientific Conf 55-58.

11. Poletayev AB (2008) Immunophysiology and Immunopathology. Med Inform Agency M pp. 205. 
12. Poletayev $A B$ (2010) Immunology of pregnancy and embryotropic autoantibodies. MEDSI Newsletter 8: 38-44.

13. Prummel M, Wirsinga V (2006) Habitual non carrying of pregnancy: can antibodies to TPO be blamed. Clinical and experimental thyroidology 2(4): 52-54.

14. Stepanova RN, Makarova OM (2010) Antinuclear autoantibodies in women suffering the usual loss of pregnancy Kursk scientific-practical bulletin "Person and his health 1: 97-99.
15. Titova LYu, Aristarkhov VG, Puzin DA (2013) Hypothyroidism and pregnancy Russian medical-biological bulletin named after academician IP Pavlov. 2: 97-101.

16. Alard JE (2007) Modulation of endothelial cell damages by anti-Hsp60 autoantibodies in systemic autoimmune diseases. Autoimmunity reviews 6(7): 438-443.

17. Cappello F (2009) Chlamydia trachomatis infection and anti-Hsp60 immunity: the two sides of the coin. Plos Pathog 5(8): e1000552.

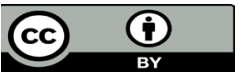

This work is licensed under Creative Commons Attribution 4.0 License

To Submit Your Article Click Here:

Submit Article

DOI: $10.32474 /$ PAPN.2020.02.000145

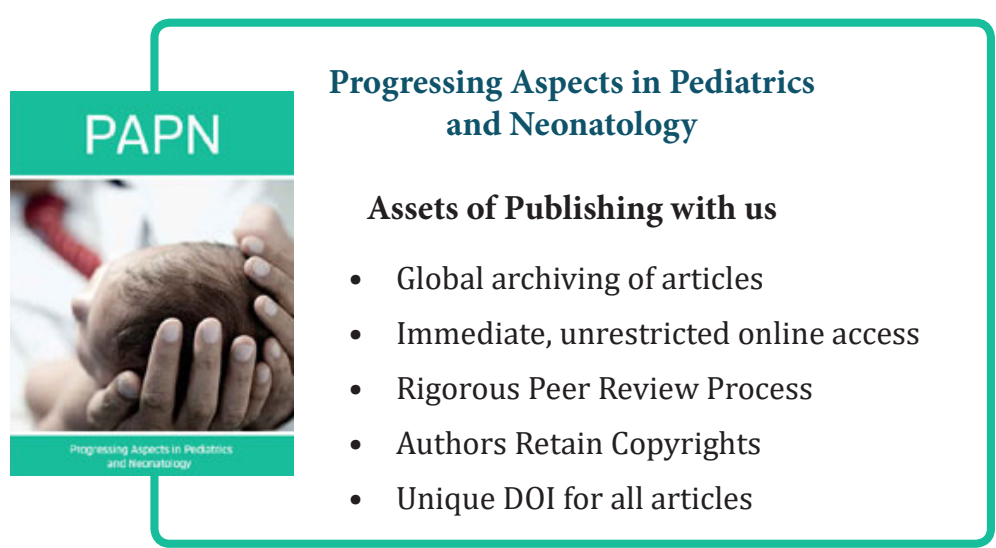

